07

\title{
Радиационная стойкость источника субтерагерцового излучения из гетеродина на генераторе на диоде Ганна и умножителя на полупроводниковой сверхрешетке
}

\author{
(C) А.С. Иванов, ${ }^{1}$ Д.Г. Павельев, ${ }^{2}$ С.В. Оболенский, ${ }^{1,2}$ Е.С. Оболенская ${ }^{2}$ \\ ${ }^{1}$ АО НПП „Салют“, \\ 603950 Нижний Новгород, Россия \\ ${ }^{2}$ Нижегородский государственный университет им. Н.И. Лобачевского, \\ 603950 Нижний Новгород, Россия \\ e-mail: ivanov.2582@yandex.ru
}

Поступило в Редакцию 30 апреля 2021 г.

В окончательной редакции 30 апреля 2021 г.

Принято к публикации 30 апреля 2021 г.

\begin{abstract}
Произведена оценка радиационной стойкости к гамма-облучению различных уровней доз $(0.5,2,10 \mathrm{kGy})$ источника субтерагерцового излучения из гетеродина на диоде Ганна и умножителя на полупроводниковой сверхрешетке GaAs/AlAs. Разработана и изготовлена измерительная камера для изучения радиационной стойкости диодов Ганна. Аналитически оценена зависимость выходной мощности от частоты субтерагерцового источника излучения до и после облучения.
\end{abstract}

Ключевые слова: радиационная стойкость, сверхрешетка, диод Ганна, терагерцы.

DOI: $10.21883 /$ JTF.2021.10.51362.133-21

\section{Введение}

На сегодняшний день источники и приемники электромагнитных волн субтерагерцового и терагерцового диапазонов с широкой полосой перестройки частоты широко используются для решения задач спектроскопии [1], радиоастрономии [2], построения систем безопасности [3] и телекоммуникаций [4,5], систем управления на поле боя [6]. Однако применение в комплексах военного и космического назначения накладывает на приемо-передающую аппаратуру жесткие требования по массогабаритным характеристикам, малым величинам питающих напряжений и стойкости к ионизирующему излучению. Одним из таких источников излучения является прибор из гетеродина на генераторе на диоде Ганна (ДГ) и умножителя на полупроводниковой сверхрешетке (ППСР) [7]. В настоящее время активно исследуется устойчивость к ионизирующим видам излучения традиционного объемного [8] и планарного ДГ [9], а также диодов на основе GaAs/AlAs-сверхрешеток [10], в настоящей работе рассматривается радиационная стойкость источника субтерагерцового диапазона на основе ДГ и ППСР.

\section{1. Подготовка эксперимента}

В качестве активного элемента для гетеродина был применен ДГ аналогичный 3А763ЛМ (разработка AО НПП „Салют“, г.Нижний Новгород). Основная частота генерации подобных диодов лежит в 8-mm диапазоне. Диод имеет вертикальную структуру, в которой контакты диода расположены на верхней и нижней грани кристалла. Диод представляет собой полупроводниковый кристалл арсенида галлия диаметром около $0.1 \mathrm{~mm}$ и толщиной 10-20 $\mu \mathrm{m}$, смонтированный на теплоотводящем кристаллодержателе - медном стержне диаметром $1.2 \mathrm{~mm}$ и высотой $2 \mathrm{~mm}$. Концентрация носителей составляет $n_{0}=8 \cdot 10^{15} \mathrm{~cm}^{-3}$, размер активной области $-3 \mu \mathrm{m}$. Все три рассмотренных в настоящей работе ДГ обладают сходными параметрами в пределах технологических погрешностей.

Для изучения рабочих параметров ДГ разработана и изготовлена измерительная камера. Особенности конструкции камеры позволяют устанавливать диод в полость отрезка перестраиваемого волновода без осуществления пайки активного элемента в пределах нескольких минут и в результате измерять характеристики ДГ для исследования радиационной стойкости неразрушающим методом. Диод устанавливается в камеру с помощью цангового зажима. Введение режекторного фильтра в запредельном для основной частоты волноводе максимально развязывает контуры по основной частоте и по второй гармонике основной частоты для осуществления независимой настройки по выходной частоте и мощности. Указанные достоинства технологической камеры расширяют область применения разработанной оснастки для проведения межоперационного контроля и сортировки выпускаемых изделий на серийном производстве.

\section{2. Методика эксперимента}

Измерение частоты генерации и мощности ДГ производились по схеме, подробно описанной в рабо- 
те [11]. При подаче напряжения смещения на диод в камере возбуждались электромагнитные колебания частотой порядка $30 \mathrm{GHz}$. СВЧ мощность с выхода камеры поступает по волноводу сечения $3.6 \times 1.8 \mathrm{~mm}$ на первичный преобразователь М5-50, преобразуется, и значение уровня выходной мощности отображается на индикаторе измерителя мощности М3-22. Измерение частоты генерации производится с помощью частотомера резонансного Ч2-26. Выделение частоты генерации ДГ осуществляется изменением положения подстроечных короткозамыкателей и частотой выходного контура. На шкале индикатора М3-22 проявляется в уменьшении в $2-3$ раза значения измеряемой мощности.

После получения зависимостей выходной мощности сигнала от частоты ДГ были подвергнуты облучению гамма-квантами с суммарными дозами: ДГ № $1-0.5$, ДГ № $2-2$, ДГ № $3-10 \mathrm{kGy}$. Спустя 6 месяцев серия измерений проведена для всех изучаемых ДГ.

\section{3. Результаты и обсуждения}

При сравнении результатов измерений рабочих параметров до и после облучения: для ДГ № 1 (рис. 1) отмечено расширение рабочей полосы частот в сравнении с параметрами до облучения, для ДГ № 2 (рис. 2) сужение полосы частот на 3.8\%, для ДГ № 3 (рис. 3 ) расширение на $6 \%$. После облучения гамма-квантами наблюдается уменьшение выходной мощности ДГ для большей части полученных зависимостей.

В работе [12] получены значения интенсивности гармоник умножителя частоты на ППСР в полосе частот 0.4-6.5 THz, в [10] приводится исследование радиационной стойкости диодов на ППСР GaAs/AlAs. На основе полученных выше зависимостей мощности от частоты генерации ДГ, учитывая характер изменения рабочих характеристик ДГ (№№ 1,2,3) до и после облучения гамма-квантами, возможно оценить зависимость мощности гармоник от частоты источника субтерагерцового

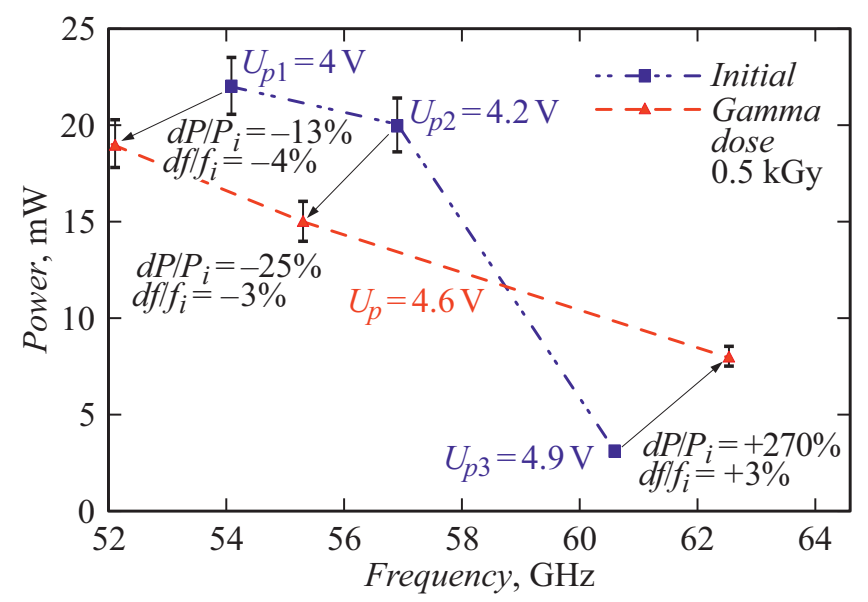

Рис. 1. Результаты измерения выходной мощности от частоты генерации для ДГ № 1.

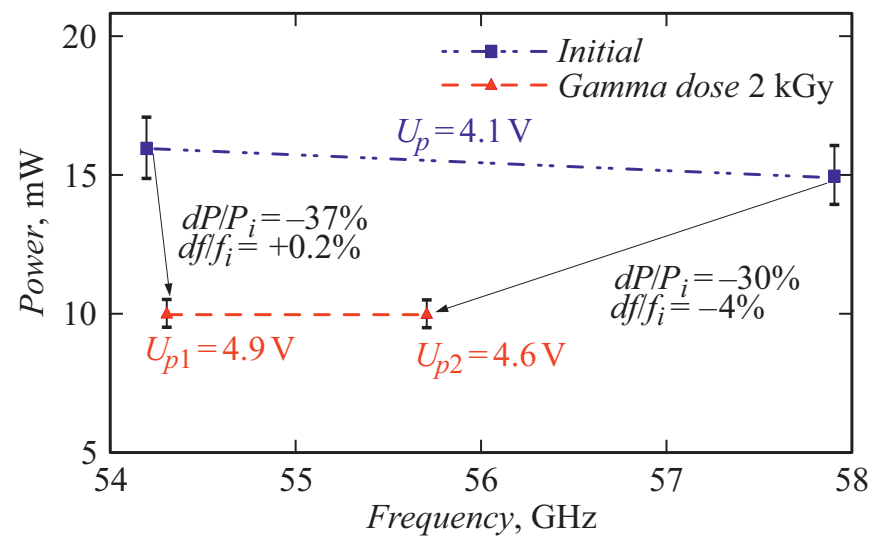

Рис. 2. Результаты измерения выходной мощности от частоты генерации для ДГ № 2.

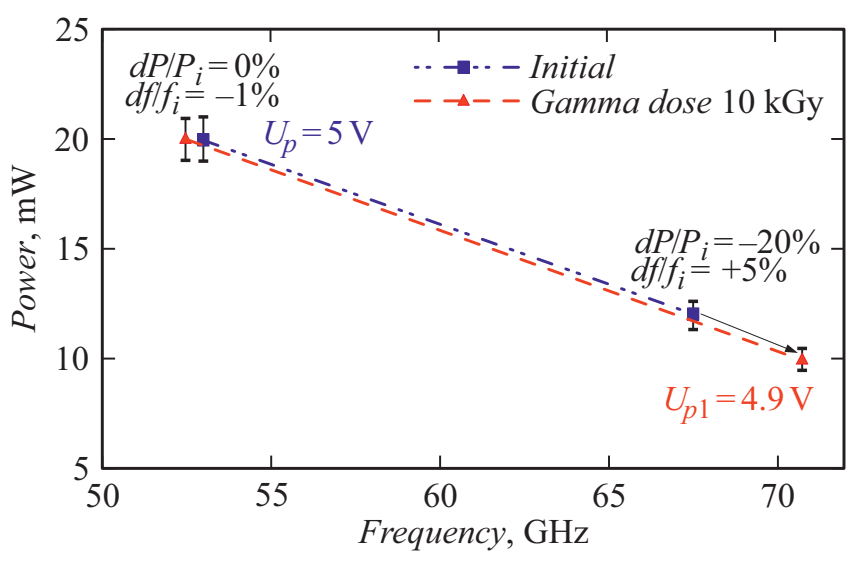

Рис. 3. Результаты измерения выходной мощности от частоты генерации для ДГ № 3.

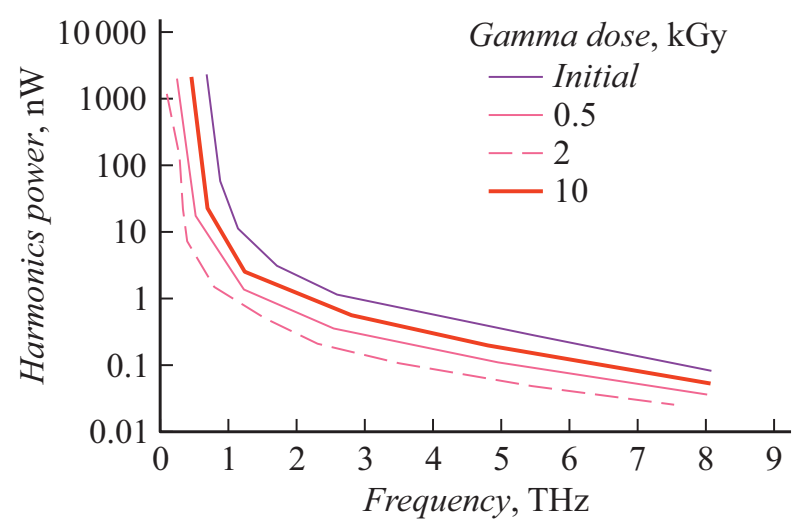

Рис. 4. Оценка зависимости мощности гармоник от частоты генерации источника субтерагерцового излучения.

излучения в составе гетеродина на ДГ и умножителя на ППСР в целом (рис. 4). В качестве опорной частоты гетеродина была выбрана третья гармоника генератора $(3.54 \mathrm{GHz})$ на ДГ в $162 \mathrm{GHz}$. Для дозы в $0.5 \mathrm{kGy} \mathrm{в}$ качестве гетеродина был выбран генератор на ДГ № 1, для дозы в $2 \mathrm{kGy}$ - ДГ № 2, $10 \mathrm{kGy}$ - ДГ № 3. При об- 
лучении гетеродина гамма-квантами дозами 0.5 и $2 \mathrm{kGy}$

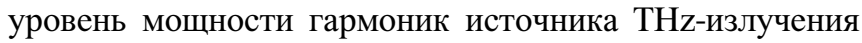
уменьшается обратно пропорционально величине дозы. Для дозы в $10 \mathrm{kGy}$ уровень мощности гармоник источника превосходит уровень для $0.5 \mathrm{kGy}$, но остается меньшим уровня до облучения.

Новизна рассматриваемой камеры заключается в возможности измерения рабочих параметров для исследования радиационной стойкости и определения параметров ДГ для проведения последующего компьютерного моделирования (программные комплексы TCAD, ATLAS).

\section{Заключение}

В работе приведены зависимости выходной мощности от частоты гетеродина на ДГ до и после облучения гамма-квантами различных интенсивностей $(0.5,2,10 \mathrm{kGy})$. На основе измерений рабочих характеристик гетеродина на ДГ и теоретических результатов радиационной стойкости ППСР сделаны выводы о радиационной стойкости к гамма-облучению источника субтерагерцового излучения в целом.

\section{Конфликт интересов}

Авторы заявляют, что у них нет конфликта интересов.

\section{Список литературы}

[1] В.Л. Вакс, Е.Г. Домрачева, Е.А. Собакинская, М.Б. Черняева. УФН, 184 (7), 139 (2014). DOI: $10.3367 /$ UFNr.0184.201407d.0739

[2] C. Risacher, V.Vassilev, R.R. Monje, I. Lapkin, V. Belitsky, A.B. Pavolotsky, M. Pantaleev, P. Bergman, S.-E. Ferm, E. Sundin, M. Svensson, M. Fredrixon, D. Meledin, L.G. Gunnarsson, M. Hagstrom, L.-A. Johansson, M. Olberg, R.S. Booth, H. Olofsson, L.-A. Nyman. Astronomy \& Astophys., 454, 17 (2016). DOI: $10.1051 / 0004-6361: 20065373$

[3] J.F. Federici, B. Schulkin, F. Huang, D. Gary, R. Barat, F. Oliveira, D. Zimdars. Semicond. Sci. Technol., 20, 266 (2005). DOI: 10.1088/0268-1242/20/7/018

[4] T. Kürner, S. Priebe. J. Infrared Milli Terahz Waves, 35, 53 (2014). DOI: 10.1007/s10762-013-0014-3

[5] C. Jastrow, K. Munter, R. Piesiewicz, T. Kurner, M. Koch, T. Kleine-Ostmann. Electron. Lett., 44, 3 (2008). DOI: 10.1049/el:20083359

[6] R.J. Fitch, R. Osiander. John Hopkins Apl. Tech. Digest, 25, 348 (2004). https://www.researchgate.net/publication/ 228861430_Terahertz_waves_for_communications_and_sensing/link/56c4becb08ae 7fd4625a4507/download

[7] V. Vaks, A. Illiyk, A.Panin, S. Pripolsin, S. Basov, D. Pavelyev. Proc. of the 37th European Microwave Conference (Munich, Germany, October 2007)

DOI: 10.1109/EUMC.2007.4405319
[8] W. Abd El-Basit, S. Mohamed El-Ghanam, A. Mosleh Abdel-Maksood, S. Abd El-Tawab Kamh, F. Abd ElMoniem, S. Soliman. Nucl. Eng. Technol., 48, 1219 (2016). DOI: $10.1016 /$ j.net.2016.04.009

[9] Е.С. Оболенская, Е.А. Тарасова, А.Ю. Чурин, С.В. Оболенский, В.А. Козлов. ФТП, $\mathbf{5 0}(12), 1605$ (2016). DOI: $10.21883 / \mathrm{ftp} .2016 .12 .43884 .30$

[10] Д.Г. Павельев, А.П. Васильев, В.А. Козлов, Е.С. Оболенская. ФТП, 52 (11), 1337 (2018). DOI: $10.21883 /$ FTP.2018.11.46595.17

[11] А.С. Иванов, С.В. Оболенский. Тез. докл.3-й Росс.-Бел. конф. „Современная элементная база радиоэлектроники и ее применение“ им. О.В. Лосева (Нижний Новгород, Россия, 2017), с. 20.

[12] А.С. Иванов, Д.Г. Павельев, Ю.И. Кошуринов, А.Н. Панин, В.Л. Вакс, В.И. Гавриленко, А.В. Антонов, В.М. Устинов, А.Е. Жуков. ФТП, 46 (1), 125 (2012). 